\title{
Research Paper: Selection Criteria of Hospital Volunteers for the Provision of Health Services in Disasters
}

Forouzandeh Jannat $^{1 *}$, Ali Ardalan², Mokhtar Malekpour ${ }^{1}$, Gholamreza Masoumi $^{3}$, Marzieh Vahid-Dastjerdi ${ }^{4}$

1. Department of Management of Healthcare Services, School of Management and Medical Information Sciences, Isfahan University of Medical Sciences, Isfahan, Iran.

2. Department of Health in Disasters and Emergencies, School of Public Health, Tehran University of Medical Sciences, Tehran, Iran

3. Department of Emergency Medicine, School of Medicine, Iran University of Medical Sciences, Tehran, Iran.

4. Department of Obstetrics and Gynecology, School of Medicine, Tehran University of Medical Sciences, Tehran, Iran.

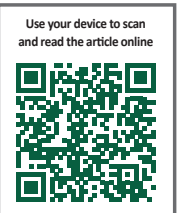

Citation: Jannat F, Ardalan A, Malekpour M, Masoumi Gh, Vahid-Dastjerdi M. Selection Criteria of Hospital Volunteers for the Provision of Health Services in Disasters. Health in Emergencies and Disasters Quarterly. 2017; 2(3): 139-144. https://doi. org/10.18869/nrip.hdq.2.3.139

https://doi.org/10.18869/nrip.hdq.2.3.139

Article info:

Received: 12 Nov. 2016

Accepted: 01 Mar. 2017

\section{Keywords:}

Volunteers, Hospital, Disasters, Selection criteria

\section{A B STRACT}

Background: Hospitals need volunteers to help the injured people during disasters. Thus, it is necessary to prepare some criteria for selecting volunteers. The purpose of this study was to determine and prioritize individual and social criteria for selection of local volunteers in hospitals before disasters, the volunteers who provide health services for victims in disasters.

Materials and Methods: This was an analytical descriptive study in which a researchermade questionnaire was used to collect the data in 2015. The statistical population consisted of emergency and health managers and experts in hospitals affiliated to Tehran University of Medical Sciences. The sample were selected using Cochrane methodology and calculated as 180 subjects. The data were analyzed through calculating mean, standard deviation, 1-sample t-test, and Friedman test using SPSS.

Results: Based on the results, most personal and social criteria were significant $(\mathrm{P} \leq 0.05)$ and important in volunteers' selection. The results showed that the most important personal criteria were physical ability and fitness, practical expertise, and voluntary attendance experience with the mean ranks of $4.03,3.94$, and 3.77 , respectively. Also among social criteria, prompt response with the mean rank of 7.26, responsibility with 6.25 , and conscience with 6.06 have been determined as important factors in the selection of volunteers for health services of hospitals in disasters.

Conclusion: Hospitals could select volunteers based on the determined criteria. Personal criteria of physical fitness and practical expertise along with social criteria of prompt response and responsibility were reliable norms that based on them, the best volunteers could be chosen to perform health duties and decrease injuries in relief and health services.

* Corresponding Author:

Forouzandeh Jannat, PhD Student

Address: Department of Management of Healthcare Services, School of Management and Medical Information Sciences, Isfahan University of Medical

Sciences, Isfahan, Iran.

E-mail: forozandejannat@gmail.com 


\section{Introduction}

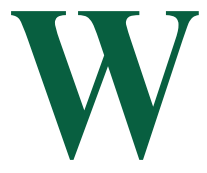

hen a disaster happens to somebody, so many relief and health services are carried out by friends, relatives, and neighbors [1]. It is impossible to predict how people respond in disasters; however, anticipating risks and preparing people to deal with these risks can improve people's responses [2, 3]. During disasters, because of the vast extent of the injuries, hospitals and health centers staff cannot usually respond to all required tasks [4]. Therefore, during disasters, volunteers are dispatched to help the affected people [5]. However, volunteers without adequate skills provide inefficient relief and health services and do not often have much use [6, 7]. Evidence has demonstrated that individuals and groups outside the disasters management system of hospitals who are interested to help during disasters, have negligible benefits and even create problems for the medical staff $[8,9]$.

Optimal performance to improve the quality of service is one of the most important factors in recruiting volunteers [10]. In order to launch volunteer center at hospitals, it is very important to select people who are able to deliver the highest performance during disasters [11]. Most recent studies have also justified why individuals' performance is a vital issue in achieving the fundamental objectives [12-14].

General review of the factors affecting volunteers' performance identified two relevant categories; personal and social characteristics [15]. Personal and social characteristics influence individuals' beliefs in organizational goals, values, and abilities, as well as their efforts to achieve these goals [16]. This explained how volunteers' personal and social features could be regarded as fundamental criteria related to action plans required for disaster management [17].

Therefore, the foremost important factor in disaster management is human resource management like relief and healthcare volunteers $[18,19]$. In other words, the volunteers have not been addressed properly and lack of volunteers' or people-oriented forces' selection model can be quite felt [20]. This weakness is also discovered by reviewing the literature. This is important because in critical situations, if there is no proper plan for volunteers and relief workers, irreparable damages may happen to the bulk of the society [21].

Due to the delicacy of the volunteer management, need for volunteer forces during disasters, and existing research gap about volunteers of relief activities, this study aimed to identify and prioritize personal and social criteria for selecting volunteers in hospitals to deal with disasters.

\section{Materials and Methods}

The research was an analytical descriptive study, carried out in 2015. The statistical population comprised emergency and health managers and experts (practitioners, nurses, healthcare center managers, and emergency experts) in hospitals affiliated to Tehran University of Medical Sciences. Tehran is the capital city of Iran with high population density, however, it is located on the earthquake zone. The sample size has been calculated as 180 subjects through Cochrane methodology. Sampling was done by simple random method.

In this study, the researchers' questionnaire involving "volunteers' personal and social criteria" was used for data collection. The researchers' questionnaire was based on Marta et al. (1999), Hughes and Black (2002), and Acharya et al. (2016) and consisted of two sections: 1) personal criteria with 5 items, 2) social criteria with 11 items $[15,17,22]$. The items were rated according to 5-point Likert-type scale from 1 to 5 (1=completely disagree to $5=$ completely agree). The Cronbach alpha was used to assess questionnaire reliability. The Cronbach alpha values were calculated for personal criteria as 0.81 and social criteria as 0.78 . The calculated Cronbach alpha indicated that questionnaire has acceptable reliability. The opinions of experts and relevant specialists were used to examine the content validity of the questionnaire. The questionnaire was given to experts and their comments were considered to increase the validity.

The obtained data were analyzed using descriptive and inferential statistics. Descriptive analyses comprised mean and standard deviation (SD). Inferential analyses were composed of 1-sample t-test and Friedman test. One-sample t-test was used to analyze the significance of personal and social criteria according to theoretical mean (according to 5-point Likert-type scale from 1 to 5, theoretical mean was equal to 3 ) and experimental mean (that is average of participants scores), $\mathrm{t} \geq 2$ and $\mathrm{P}<0.05$ were considered as the level of significance at $95 \%$. The Friedman test was used to prioritize the criteria of volunteers. All data were analyzed by SPSS 20.

\section{Results}

Descriptive analysis of study participants showed that $3 \%$ of them were below 25 years old, 39.4\% were between 26 and 35 years old, $32.2 \%$ were between 36 and 
45 years old, and $20.0 \%$ were over 46 years old. About $65.6 \%$ of participants were males and $34.4 \%$ females. Around $17.3 \%$ were general practitioners, $23.9 \%$ medical specialists, $36.1 \%$ nurses, $13.3 \%$ healthcare center managers, and $9.4 \%$ emergency experts. About $15.6 \%$ of the sample were working full-time and $84.4 \%$ part-time. In addition, $65 \%$ of participants had $\mathrm{PhD}, 8.3 \% \mathrm{MS}$, and $26.7 \% \mathrm{BS}$. It is noteworthy that $28.3 \%$ of the participants had less than 5 years experience, $21.1 \%$ between 6 and 10 years, $34.4 \%$ between 11 and 20 years, and $16.1 \%$ between 21 and 30 years. Finally, in the sample, $8.9 \%$ of the participants had the experience of voluntary activities, while $91.1 \%$ did not. In continuation, the descriptive and inferential analysis of personal and social criteria of local volunteers are reported based on the experts' opinion.

Table 1 presents the results of descriptive analysis and t-test of personal and social criteria. The results of mean \pm SD were $4.67 \pm 0.54$ for physical ability and fitness and $4.75 \pm 0.29$ for prompt response. One-sample t-test indicates that among personal criteria, high education $(\mathrm{P}=0.061)$ and theoretical expertise $(\mathrm{P}=0.072)$ are not significant, however other criteria are statistically significant and there is a significant difference between theoretical mean [3] and experimental mean $(\mathrm{P} \leq 0.05)$. The results of 1-sample t-test for social criteria showed that high public relations $(\mathrm{P}=0.062)$ and lack of criminal record $(\mathrm{P}=0.081)$ are not statistically significant. Also other social criteria for local volunteers are statistically significant $(\mathrm{P} \leq 0.05)$, in other words, mean of criteria are greater than theoretical mean [3].

The Friedman test was used to prioritize the personal and social criteria for volunteers. Table 2 presents the results of Friedman test and priority of personal and social criteria. Among personal criteria, physical ability and fitness with the mean rank of 4.03, practical expertise with 3.94, and voluntary attendance experience with 3.77 had the highest ranks, respectively. Among social criteria the highest rank is related to prompt response with the mean rank of 7.26. Other social criteria in order of priority were responsibility (6.25), conscience (6.06), honesty (5.91), ethical commitment (5.38), sense of cooperation (4.95), and spirit of forgiveness and sacrifice (4.76).

Table 1. Mean and the significance of personal and social criteria of volunteers

\begin{tabular}{|c|c|c|c|c|}
\hline Criteria & Measures & $\mathrm{M}(\mathrm{SD})$ & $\mathbf{t}$ & $\mathbf{P}$ \\
\hline \multirow{5}{*}{ Personal } & High education & $2.70(0.69)$ & -1.51 & 0.061 \\
\hline & Theoretical expertise & $2.40(0.64)$ & -1.42 & 0.072 \\
\hline & Practical expertise & $4.58(0.74)$ & 8.45 & 0.000 \\
\hline & Physical ability and fitness & $4.67(0.54)$ & 4.24 & 0.001 \\
\hline & Voluntary attendance experience & $4.56(0.74)$ & 6.37 & 0.000 \\
\hline \multirow{11}{*}{ Social } & Responsibility & $4.69(0.57)$ & 3.20 & 0.001 \\
\hline & Sense of cooperation & $4.33(0.55)$ & 3.98 & 0.002 \\
\hline & Composure & $4.28(0.52)$ & 3.05 & 0.000 \\
\hline & Speed action & $4.75(0.29)$ & 9.57 & 0.000 \\
\hline & Self-confidence & $3.63(0.87)$ & 8.85 & 0.000 \\
\hline & High public relations & $3.03(0.83)$ & 0.62 & 0.062 \\
\hline & Work conscience & $4.67(0.47)$ & 7.66 & 0.003 \\
\hline & Ethical commitment & $4.41(0.67)$ & 8.12 & 0.000 \\
\hline & Honesty & $4.61(0.48)$ & 4.48 & 0.023 \\
\hline & Spirit of forgiveness and sacrifice & $4.25(0.58)$ & 9.03 & 0.000 \\
\hline & Lack of criminal record & $2.34(0.56)$ & -1.63 & 0.081 \\
\hline
\end{tabular}


Table 2. The prioritization of personal and social criteria for choosing volunteers

\begin{tabular}{|c|c|c|c|}
\hline Criteria & Measures & Mean Rank & Rank \\
\hline \multirow{5}{*}{ Personal } & High education & 1.78 & 4 \\
\hline & Theoretical expertise & 1.49 & 5 \\
\hline & Practical expertise & 3.94 & 2 \\
\hline & Physical ability and fitness & 4.03 & 1 \\
\hline & Voluntary attendance experience & 3.77 & 3 \\
\hline \multirow{9}{*}{ Social } & Responsibility & 6.25 & 2 \\
\hline & Sense of cooperation & 4.95 & 6 \\
\hline & Speed action & 7.26 & 1 \\
\hline & Self-confidence & 3.33 & 8 \\
\hline & Conscience & 6.06 & 3 \\
\hline & Ethical commitment & 5.38 & 5 \\
\hline & Honesty & 5.91 & 4 \\
\hline & Spirit of forgiveness and sacrifice & 4.76 & 7 \\
\hline & Lack of criminal record & 2.98 & 9 \\
\hline
\end{tabular}

\section{Discussion}

This research was conducted on emergency and health managers and experts in hospitals of Tehran, Iran, during 2015. In this study, selection criteria of hospital volunteers before disasters were identified and prioritized. To be selected, volunteers should adopt specific criteria. The importance of each criterion is determined by ranking of measures.

According to the study results, most personal and social criteria have had significant importance in volunteers' selection. The findings show that most personal criteria are statistically significant except high education and theoretical expertise. In fact in experts' view, among the personal factors, "high education" and "theoretical expertise" were less important. The studies of Acharya et al. [22] and Kang and Cho [23] have emphasized the preliminary level of education for volunteers but has been stated that high level of education for all volunteers is not necessary. These findings were consistent with the finding of the present study.

The most effective personal criteria are physical ability and fitness in selecting volunteers. Physical fitness provides ability to perform better tasks and also prevents the physical injuries and damages. The situation is quite critical and unpredictable problems happen in disasters. Sauer et al. [24] showed that volunteers who want to help injured people, it is necessary to have good physical abilities and features.

Another important personal factor is practical expertise. As it is clear, practical expertise is more important than theoretical expertise. Education and theoretical knowledge cannot necessarily increase the ability of volunteers [25]. It is important that volunteers learn practical and specialized knowledge to deal with disasters [26]. Lack of practical expertise and knowledge in different critical situations could reduce the speed and accuracy in relief missions. The results were consistent with the study of Marta et al. [15].

Among social criteria, most were appropriate in choosing best volunteers. However, some social criteria could not be considered as social factors. For example, lack of criminal record and high public relations were not consistent with other measures and could not be considered as social criteria for volunteers' selection. The most important social characteristic is prompt response. In disasters, it is necessary to return the normal situation as soon as possible, so speed in relief and health services 
is very important [27]. Slow response and negligence in the relief and health services may endanger the lives of the people. Volunteers must be able to provide immediate measures to assist the injured people [28].

The responsibility was recognized as the next important social criteria in the selection of volunteers. Responsibility is an inner obligation to properly perform all duties undertaken. Volunteers with less responsibility may leave duties. It is necessary to prepare scale for selecting volunteers according to responsibility. The study of Hiatt et al. [29] emphasized on marital status and responsibility of volunteers and indicated that married volunteers had more responsibility and stayed with the program significantly longer than single volunteers. The third social characteristic is conscience. Conscience prioritizes thinking over acting, delays satisfaction of the desires and complies with laws and norms of the organization. In other words, people with conscience act according to obligations and duties. Other social criteria were honesty, ethical commitment, sense of cooperation, and spirit of forgiveness and sacrifice that can be considered in selecting volunteers. These results were consistent with previous studies [17, 30] that demonstrated having religious involvement, ethical commitment, sense of cooperation, and forgiveness were important social characteristic for volunteers.

\section{Conclusion}

There are different criteria to choose appropriate volunteers. This study investigated personal and social criteria. Before disasters we need to select and manage useful volunteers for provision of health services. In this regard, hospitals and health centers should select local people as volunteers before disasters based on the priorities of the obtained criteria.

To achieve this purpose, physical ability and fitness, practical expertise, and voluntary attendance experience could be considered as important personal criteria for the selection of volunteers. Moreover, it is necessary to consider social criteria, including prompt response, responsibility, and conscience. According to the results, we suggest that before disasters, hospitals should assess interested people properly and select volunteers based on the above criteria.

Despite the obtained results, it is necessary to address the limitations of the study. Because research topic is new, similar studies in the field of hospital's volunteers, especially in Iran were few. Also the study data were merely collected through questionnaires, thus other data collection tools such as interviews and observations could provide more accurate and even different results. It is recommended that future studies investigate the crisis committees and their role in crisis management, to examine crisis committee processes and their relationship with crisis situations, and to identify the role of volunteers as one of the major parts of crisis committees in hospitals.

\section{Acknowledgments}

This study is part of $\mathrm{PhD}$ thesis approved and supported by Shakhes Pajouh Research Institute, University of Isfahan, Iran. The authors express their appreciation to authorities and staff of hospital affiliated to Tehran University of Medical Sciences for participation and collaboration in this research.

\section{Conflict of Interest}

The authors declared no conflicts of interest.

\section{References}

[1] Stallings RA, Quarantelli EL. Emergent citizen groups and emergency management. Public Administration Review. 1985; 45:93-100. doi: 10.2307/3135003

[2] Aminizadeh M, Mahmoodzadeh A, Saberinia A, Aminizadeh A. [Relationship motivation and satisfaction factors with health volunteers in kerman Province in disaster (Persian)]. Journal of Management and Medical Informatics School. 2014; 2(1):57-65.

[3] Auf der Heide E. The importance of evidence-based disaster planning. Annals of Emergency Medicine. 2006; 47(1):34-49. doi: 10.1016/j.annemergmed.2005.05.009

[4] Farajollah F, Sadeghi Nikpei N, Alamdari S. [Identify effective factors to attract public volunteer groups for giving voluntarily services in Red Crescent society (Persian)]. Quarterly Scientific Journal of Rescue \& Relief. 2009; 1(2):39-53.

[5] Helsloot I, Ruitenberg A. Citizen response to disasters: A survey of literature and some practical implications. Journal of Contingencies and Crisis Management. 2004; 12(3):98-111. doi: 10.1111/j.0966-0879.2004.00440.x

[6] Whittaker J, McLennan B, Handmer J. A review of informal volunteerism in emergencies and disasters: Definition, opportunities and challenges. International Journal of Disaster Risk Reduction. 2015; 13:358-68. doi: 10.1016/j.ijdrr.2015.07.010

[7] Wilson J, Musick M. Who Cares: Toward an integrated theory of volunteer work. American Sociological Review. 1997; 62(5):694. doi: $10.2307 / 2657355$

[8] Scanlon J, Helsloot I, Groenendaal J. Putting it all together: Integrating ordinary people into emergency response. International Journal of Mass Emergencies \& Disasters. 2014; 32(1): $43-63$ 
[9] Nivolianitou Z, Synodinou B. Towards emergency management of natural disasters and critical accidents: The Greek experience. Journal of Environmental Management. 2011; 92(10):2657-65. doi: 10.1016/j.jenvman.2011.06.003

[10] Feng B, Jiang ZZ, Fan ZP, Fu N. A method for member selection of cross-functional teams using the individual and collaborative performances. European Journal of Operational Research. 2010; 203(3):652-61. doi: 10.1016/j.ejor.2009.08.017

[11] Kahya E. The effects of job performance on effectiveness. International Journal of Industrial Ergonomics. 2009; 39(1):96-104. doi: 10.1016/j.ergon.2008.06.006

[12] De Araújo MSG, Lopes PMPR. Virtuous leadership, organizational commitment and individual performance. Tékhne. 2014; 12(1):3-10. doi: 10.1016/j.tekhne.2015.01.008

[13] Sahusilawane W. The impact of effectiveness to use and trust of local financial and information system (SIKD) to individual performance in southeast Moluccas. Procedia - Social and Behavioral Sciences. 2015; 211:960-5. doi: 10.1016/j. sbspro.2015.11.127

[14] Chiniara M, Bentein K. Linking servant leadership to individual performance: Differentiating the mediating role of autonomy, competence and relatedness need satisfaction. The Leadership Quarterly. 2016; 27(1):124-41. doi: 10.1016/j. leaqua.2015.08.004

[15] Marta E, Rossi G, Boccacin L. Youth, solidarity, and civic commitment in Italy: An analysis of the personal and social characteristics of volunteers and their organizations. In: M. Yates, J. Youniss editors. Roots of Civic Identity. New York: Cambridge University Press; 1999. doi: 10.1017/ cbo9780511751820.006

[16] Garcia C, Rabadi G. Optimising coordinated multi-team volunteer scheduling: A combined constraint programming and goal programming approach. International Journal of Industrial and Systems Engineering. 2011; 9(2):183. doi: 10.1504/ijise.2011.042834

[17] Hughes P, Black A. The impact of various personal and social characteristics on volunteering. Australian Journal on Volunteering. 2002; 7(2):59-69.

[18] Alexander D. The voluntary sector in emergency response and civil protection: Review and recommendations. International Journal of Emergency Management. 2010; 7(2):151. doi: 10.1504/ijem.2010.033654

[19] Haraoka T, Ojima T, Murata C, Hayasaka S. Factors influencing collaborative activities between non-professional disaster volunteers and victims of earthquake disasters. PLoS ONE. 2012; 7(10):e47203. doi: 10.1371/journal.pone.0047203

[20] Ramazaninejad R, Alaadin P. [Effective factors in level of participation of volunteers of the Red Crescent (Persian)]. Quarterly Scientific Journal of Rescue \& Relief. 2009; 1(1):28-34.

[21] Hotchkiss RB, Fottler MD, Unruh L. Valuing volunteers: the impact of volunteerism on hospital performance. Academy of Management Proceedings. 2008; 2008(1):1-6. doi: 10.5465/ambpp.2008.33725078

[22] Acharya D, Singh JK, Adhikari S, Jain V. Association between sociodemographic characteristics of female community health volunteers and their knowledge and performance on maternal and child health services in rural Nepal. Journal of Multidisciplinary Healthcare. 2016; 111. doi: 10.2147/ jmdh.s98700
[23] Kang HJ, Cho SJ. Differences in durability based on characteristics of volunteers in their 40s and 50s. Advanced Science and Technology Letters. 2016; 131:64-8. doi: 10.14257/ astl.2016.131.13

[24] Sauer LM, Catlett C, Tosatto R, Kirsch TD. The utility of and risks associated with the use of spontaneous volunteers in disaster response: A survey. Disaster Medicine and Public Health Preparedness. 2014; 8(1):65-9. doi: 10.1017/ dmp.2014.12

[25] Meyer M, Peek L, Unnithan NP, Coşkun R, Tobin-Gurley J, Hoffer K. Planning for diversity: Evaluation of a volunteer disaster response program. Journal of Cultural Diversity. 2016; 23(3):106-13.

[26] Masoumi G, Ardalan A, Jannat F. Simple and advanced triage in occurrence of natural disasters and examine the role of volunteers. International Journal of Current Life Sciences. 2014; 4(5):2169-71.

[27] Ocak T, Duran A, Ozdes T, Hocagil C, Kucukbayrak A. Problems encountered by volunteers assisting the relief efforts in Van, Turkey and the surrounding earthquake area. Journal of Academic Emergency Medicine. 2013; 12(2):66-70. doi: 10.5152/jaem.2013.029

[28] Rogstadius J, Teixeira C, Karapanos E, Kostakos V. An introduction for system developers to volunteer roles in crisis response and recovery. Paper presented at: The $10^{\text {th }}$ International Conference on Information Systems for Crisis Response and Management. 12-15 May 2013; Baden, Germany.

[29] Hiatt SW, Michalek P, Younge P, Miyoshi T, Fryer E. Characteristics of volunteers and families in a neonatal home visitation project: The Kempe community caring program. Child Abuse \& Neglect. 2000; 24(1):85-97. doi: 10.1016/s01452134(99)00114-3

[30] Liu Y. A proposal for a spiritual care assessment toolkit for religious volunteers and volunteer service users. Journal of Religion and Health. 2013; 53(5):1414-26. doi: 10.1007/ s10943-013-9760-8 